Published in final edited form as:

Glia. 2003 October ; 44(1): . doi:10.1002/glia.10266.

\title{
Regulation of Tissue Inhibitor of Metalloproteinase-1 by Astrocytes:
}

\author{
Links to HIV-1 Dementia
}

\section{RADHIKA SURYADEVARA ${ }^{1,2,3}$, SPRING HOLTER ${ }^{1,2,3}$, KATHLEEN BORGMANN $^{1,2,3}$, RAISA PERSIDSKY ${ }^{1,2,3}$, CHRISTINE LABENZ-ZINK ${ }^{1,2,3}$, YURI PERSIDSKY ${ }^{2,3}$, HOWARD E. GENDELMAN $^{2,3,4}$, LI WU $1,2,3$, and ANUJA GHORPADE ${ }^{1,2,3,{ }^{*}}$ \\ ${ }^{1}$ Laboratory of Cellular Neuroimmunology, University of Nebraska Medical Center, Omaha, Nebraska}

${ }^{2}$ Center for Neurovirology and Neurodegenerative Disorders, University of Nebraska Medical Center, Omaha, Nebraska

${ }^{3}$ Department of Pathology and Microbiology, University of Nebraska Medical Center, Omaha, Nebraska

${ }^{4}$ Department of Medicine, University of Nebraska Medical Center, Omaha, Nebraska

\section{Abstract}

The neuropathogenesis of HIV-1-associated dementia (HAD) revolves around the secretion of toxic molecules from infected and immune-competent mononuclear phagocytes. Astrocyte activation occurs in parallel but limited insights are available for its role in neurotoxicity and cognitive dysfunction. One means in which astrocytes may affect disease is through their production of tissue inhibitors of metalloproteinases (TIMPs). TIMPs are regulators of matrix metalloproteinases, enzymes that affect blood-brain barrier integrity through altering the extracellular matrix. We hypothesized that in response to injury and inflammation in HAD, astrocytes regulate the production of TIMP-1, the inducible type of TIMP that is important in inflammation. To address astrocyte-mediated TIMP-1 regulation in HAD, we evaluated the responses of primary human to IL- $1 \beta$ and HIV-1. TIMP-1 levels in plasma, CSF, and brain tissue of control, HIV-1 infected patients without cognitive impairment, and HAD patients were also studied. Our data show that an upregulation of TIMP-1 results from astrocytes acutely activated with IL-1 $\beta$. In contrast, CSF and brain tissue samples from HAD patients showed reduced TIMP-1 levels compared to seronegative controls. MMP-2 levels in brains showed the opposite. Consistent with this, prolonged activation of astrocytes led to a reduction in TIMP-1 and MMP-2, but a sustained elevation in MMP-1. Our data suggest that in diseased brain tissue, the ability of astrocytes to counteract the destructive effects of MMP through expression of TIMP-1 is diminished by chronic activation. Our studies reveal new opportunities for repair-based therapeutic strategies in HAD.

\section{Keywords}

astrogliosis; matrix metalloproteinase; neurodegenerative disorders; HIV-1

"Correspondence to: Anuja Ghorpade, Laboratory of Cellular Neuroimmunology, 985215 Nebraska Medical Center, Omaha, NE 68198.aghorpad@unmc.edu. 


\section{INTRODUCTION}

Activated brain mononuclear phagocytes (MPs) and glia play a role in the pathogenic events associated with HIV-1-associated dementia (HAD) (Dickson et al., 1993; Gelbard et al., 1994; Shrikant et al., 1996; Persidsky et al., 1999; Persidsky and Ghorpade, 2001). The effector mechanisms by which infected and immune-activated MPs contribute to HAD are numerous and incessant. The role that astrocytes play in disease is less clearly understood. Work in the field has focused on MP-mediated damage caused by eicosinoids, quinolinic acid, platelet activating factor (PAF), tumor necrosis factor (TNF)- $\alpha$, nitric oxide, matrix metalloproteinases (MMPs), and other neurotoxins (Gendelman et al., 1997). In the tissue microenvironment, the proteolytic activity of MMPs responsible for extracellular matrix (ECM) degradation may be affected by both MPs and astrocytes. For MPs, regulation of MMP expression occurs as a consequence of cellular differentiation, activation, and viral infection (Vos et al., 2000; Ghorpade et al., 2001). We and others have found higher levels of both MMP-2 and pro-MMP-9 activity in the CSF of individuals with HAD, as compared to non-demented seropositive or seronegative controls (Conant et al., 1999). This upregulation of MMPs in HAD has direct implications for monocyte migration, which involves the activity of both MMPs and tissue inhibitors of metalloproteinases (TIMPs) in the degradation of the ECM (Kintscher et al., 2001). MMP activity is affected by the tissue inhibitors of metalloproteinases (TIMP-1-4) (Wojtowicz-Praga et al., 1997; Bode et al., 1999b). TIMP-1 and TIMP-2 possess the potential to inhibit the activities of all known MMPs and play an essential role in maintaining the balance between ECM degradation and formation (Gomez et al., 1997). TIMP-1 can also be regulated by growth factors and proinflammatory cytokines (Bugno et al., 1999). TIMP-1 is inducible and has been implicated in inflammatory reactions, as opposed to TIMP-2, which is constitutively expressed (Gomez et al., 1997). TIMP-3 is the only TIMP that binds exclusively to ECM components and may serve as a marker for terminal differentiation (Gomez et al., 1997; Brew et al., 2000). TIMP-4, the most recently discovered, may be involved via tissue specificity in ECM homeostasis (Gomez et al., 1997).

Imbalances between MMPs and TIMPs are connected to the degradation of ECM and are associated with arthritis, angiogenesis, and metastasis (Bode et al., 1999a,b; Fassina et al., 2000; Bloomston et al., 2002). TIMPs control cell proliferation, cell survival, and apoptosis and function as guardians against tissue degradation (Fassina et al., 2000).

Among the family of tissue inhibitors, TIMP-1 is widely implicated in a variety of inflammatory diseases and carcinogenesis (Johnatty et al., 1997; Kugler, 1999; Groft et al., 2001). In the present study, we focused our investigation on the balance between MMP and TIMP-1 in HAD. Many accept that the production of TIMP-1 is a protective response, and astrocytes are believed to be the predominant cell type responsible for TIMP-1 production in the CNS (Rivera et al., 1997; Pagenstecher et al., 1998). Although several groups and unpublished data from our laboratory have shown that microglia do express TIMP-1, a dichotomy exists in MMP/TIMP-1 expression. Indeed, in murine CNS injury models, MMPs are usually restricted to leukocytes and microglia in CNS lesions, whereas TIMP-1 is restricted to astrocytes (Pagenstecher et al., 1998). However, endothelial cells, astrocytes, and neurons all can produce MMPs and participate in ECM remodeling, homeostasis, and disease processes in the CNS. Furthermore, reactive astrogliosis is a stereotypical response to any type of CNS injury (Norenberg, 1994; Ridet et al., 1997), and production of TIMP-1 by activated astrocytes would additionally serve in remodeling of brain ECM. Indeed, in situ immunolocalization studies have demonstrated that reactive astrocytes in animal models of CNS injury are known to produce TIMP-1 (Rivera et al., 1997; Pagenstecher et al., 1998; Jaworski, 2000). We therefore hypothesize that within the context of HAD, TIMP-1 expression by astrocytes is likely altered within the CNS even though astrocytes are rarely 
infected, with HIV-1. To these ends, we used primary human fetal astrocytes in vitro to assay the effects of immune activation in the context of HIV-1 on TIMP-1 expression. IL-1 $\beta$ was used to mimic immune activation in diseased brain. IL-1 expression is upregulated in at least eight major diseases of the brain from epilepsy to HAD (Vitkovic et al., 2000). In order to determine biological relevance, we used CSF, as well as human brain tissue RNA and protein lysates from seronegative controls, HIV-1-seropositive individuals without cognitive deficits, and HAD patients to confirm our in vitro observations. The results corroborate our hypothesis that under disease conditions acute immune activation of astrocytes increases TIMP-1 as an attempted repair response. However, with chronic activation, as observed in CSF and brain tissues from patients with end-stage neurological disease, this response fails and ultimately leads to exacerbation of disease. Further investigation aimed at discovering the mechanism of differential TIMP-1 regulation may lead to identification of new therapeutic targets.

\section{MATERIALS AND METHODS}

\section{Viral Isolates, Cerebrospinal Fluid, Plasma Specimens}

Four different HIV-1 strains, HIV-1 ADA $_{\text {(plasma) (Gendelman et al., 1988b), HIV-1 }}$ SF162 (CSF) (Cheng-Mayer et al., 1988), HIV-1 JRFL (Koyanagi et al., 1987), and HIV-1 $1_{\text {DJV }}$ (brain tissue) (Heinzinger et al., 1995), were used to study tissue-specific differences. All viral strains were propagated in monocyte-derived macrophages (MDMs). All virions were centrifuged and purified to obtain clarified virus preparations that were normalized on the basis of reverse transcriptase (RT) activity. HIV-1 $1_{\mathrm{ADA}}, \mathrm{HIV}-1_{\mathrm{DJV}}, \mathrm{HIV}-1_{\mathrm{JRFL}}$, and HIV-1 ${ }_{\text {SF162 }}$ preparations were kindly provided by the National Neurological Tissue Repository. The NIH National NeuroAIDS Tissue Consortium provided the CSF, plasma, and brain specimens. The Center for Neurovirology and Neurodegenerative Disorders (CNND) Brain Bank also provided brain tissue.

\section{Isolation and Cultivation of Human Fetal Astrocytes}

Human astrocytes were obtained from second-trimester elective abortus brain tissue in full compliance with the ethical guidelines of the NIH and the University of Nebraska Medical Center. Specimens were dissected and mechanically dissociated by teasing through a Nitex bag and a $70 \mu \mathrm{m}$ sieve. The cell suspension was centrifuged, resuspended in media, and plated at a density of $2 \times 10^{7}$ cells $/ 150 \mathrm{~cm}^{2}$. Nonadherent microglia and oligodendrocytes were removed by gentle agitation. The adherent astrocytes were treated with trypsin and cultured under similar conditions to enhance the purity of replicating astroglial cells. The purity of these astrocyte preparations was routinely $>98 \%$ by immunocyto-chemical staining for glial fibrillary acid protein (GFAP; Fig. 1A) (Persidsky et al., 1999; Canki et al., 2001).

\section{Isolation and Propagation of Human Monocytes}

Peripheral blood mononuclear cells were obtained from HIV-1, HIV-2, and hepatitis Bseronegative donors by leukopheresis. The monocytes were then purified by countercurrent centrifugal elutriation (Gendelman et al., 1988b). Cell suspensions were $>98 \%$ pure monocytes by Wright-staining, nonspecific esterase, granular peroxidase, and CD68 immunostaining. Cells were cultured for 7 days in Dulbecco's modified Eagle's media (Sigma, St. Louis, MO) supplemented with 10\% heat-inactivated pooled human serum, 10 $\mu \mathrm{g} / \mathrm{ml}$ ciprofloxacin (Sigma), $50 \mu \mathrm{g} / \mathrm{ml}$ gentamicin (Sigma), and 1,000 U/ml macrophage colony-stimulating factor (MCSF), a generous gift from Genetics Institute (Cambridge, MA). After 7 days, cells were maintained in MCSF-free media, as monocytes produce endogenous MCSF after cell cultivation. All reagents were pre-screened and found negative 
for endotoxin ( $<10 \mathrm{pg} / \mathrm{ml}$; Associates of Cape Cod, Falmouth, MA) and mycoplasma contamination (Gen-probe, San Diego, CA).

\section{HIV-1 Infection of MDM}

Monocytes were cultured on 96-well plates (Costar, Cambridge, MA) at a density of $10^{5}$ cells/well for 7 days prior to viral infection. The cell-free viral inoculum was standardized for all experiments by RT activity $\left(2 \times 10^{5} \mathrm{cpm} / 10^{6}\right.$ cells $)$. Adherent MDM were incubated with virus for $4 \mathrm{~h}$ at $37^{\circ} \mathrm{C}$. Culture medium was exchanged twice weekly. RT was determined every 2-3 days using $10 \mu \mathrm{l}$ each of the collected sample (Kalter et al., 1991; Ghorpade et al., 1998).

\section{Preparation of Brain Tissue Extracts}

Frontal cortex and basal ganglia specimens were provided by the National NeuroAIDS Consortium and the CNND Brain Bank. Frontal cortex, cerebellum, and white matter were also obtained from a patient with HIV-1 encephalitis (HIVE). Autopsy was performed within $3 \mathrm{~h}$ after death. Samples were homogenized in lysis buffer [1\% Triton-X100 and 1 $\mathrm{mM}$ phenylmethylsulfonyl fluoride (PMSF) in $\mathrm{Mg} / \mathrm{Ca}$-free phosphate-buffered saline]. Supernatants were then centrifuged at $15,000 \mathrm{rpm}$ for $10 \mathrm{~min}$ at $4^{\circ} \mathrm{C}$. Clarified supernatants were collected and the protein concentration was determined by standard Bicinconic Acid (BCA) methods (Pierce, Rockford, IL).

\section{Quantikine mRNA ELISA Tests}

Total cellular RNA was isolated from human astrocytes and human brain tissue using the standard TRIzol method (Chadderton et al., 1997). For the measurement of GAPDH, a housekeeping gene used for normalization, and IL- $1 \beta$ transcripts in human brain tissue, quantikine mRNA ELISA determinations were used. ELISA kits were purchased from R\&D Systems (Minneapolis, MN) and performed according to the manufacturer's instructions. ELISA determinations yielded absolute quantities of mRNA for the specific transcript of interest in units of amol/ml.

\section{Analyses of GFAP and TIMP-mRNA}

Levels of GFAP mRNA in human brain autopsy tissue were determined after RT with antisense primers and PCR amplification of the cDNA. Data were quantified using a Molecular Dynamics PhosphorImager Storm system (Ghorpade et al., 2001). TIMP-1 levels in primary astrocytes were assayed by RT-PCR reactions. The following primer sequences were utilized: GFAP, antisense (5'-GTGGATCTTCCTCAAGAACC-3') and sense (5'AGAGGGACAATCTGGCACAGG-3'); TIMP-1, antisense (5'CGTCCACAAGCAATGAGTGCC-3') and sense (5'GGACACCAGAAGTCAACCAGACC-3'). In order to establish the validity of differences in the levels of GFAP or TIMP-1, results were normalized to GAPDH transcript levels as determined by the quantikine mRNA ELISA supplied by R\&D Systems. Amplified DNAs were identified by Southern blotting. For RT-PCR, total cellular RNA $(0.5 \mu \mathrm{g})$ in $2.5 \mu \mathrm{l}$ was mixed with $0.25 \mu \mathrm{g}$ of antisense primers. RT ( $0.5 \mu \mathrm{l}$ of $200 \mu / \mu \mathrm{l}$; Invitrogen, Carlsbad, CA) and $0.75 \mu \mathrm{l}$ each of the four deoxynucleotide triphospathes $(10 \mathrm{mM}$; Perkin Elmer, Boston, MA) were added. The mixture was heated at $70^{\circ} \mathrm{C}$ for $10 \mathrm{~min}$, then cooled to $4^{\circ} \mathrm{C}$. RT reactions were performed at $37^{\circ} \mathrm{C}$ for $15 \mathrm{~min}$ and were terminated by heating the sample to $95^{\circ} \mathrm{C}$. For PCR amplification of the cDNAs, $0.5 \mu \mathrm{g}$ sense and $0.25 \mu \mathrm{g}$ antisense primers were added, with $1 \mu \mathrm{l}$ each of the four deoxynucleotide triphosphates and $0.5 \mu \mathrm{l}$ Amplitaq DNA polymerase ( $5 \mathrm{U} / \mu \mathrm{l}$; Perkin Elmer, Gaithersburg, MD). A total of 28 cycles were performed at $94^{\circ} \mathrm{C}$ for $30 \mathrm{~s}, 50^{\circ} \mathrm{C}$ for $30 \mathrm{~s}$, and $72^{\circ} \mathrm{C}$ for $1 \mathrm{~min}$. Reactions were then held at $4^{\circ} \mathrm{C}$. 


\section{Measurement of TIMP-1, MMP-2, and MMP-1}

TIMP-1 was assayed by ELISA (Amersham Biosciences, Piscataway, NJ, and Oncogene Research Products, Boston, MA). MMP-2 and MMP-1 were measured in the same samples using ELISA kits from Oncogene. The values obtained were normalized to the cell number on the basis of MTT activity (Manthrope et al., 1986). Statistical analyses were performed with GraphPad Prism 3.0, with one-way analysis of variance (ANOVA) and Newman Keuls post-test. Reverse Zymography for TIMP-1 levels was performed (Kossakowska et al., 1998) with minor modifications. Polyacrylamide gels (15\%) supplemented with gelatin and purified recombinant gelatinase A were prepared to analyze samples. TIMP-1 was visualized as bands on a clear background. This was due to the inhibition of gelatinase activity and the resultant protection of gelatin clearance.

\section{RESULTS}

\section{Activated Astrocytes Produce TIMP-1}

IL-1 $\beta$ was used to mimic the immune activation present in diseased brain tissue. Highly pure preparations of astrocytes were used for all studies (Fig. 1A). Levels of TIMP-1 mRNA were analyzed by RT-PCR. For analyses of TIMP-1 secretory profiles, ELISA and reverse zymography were used. In order to determine the appropriate dosage of IL-1 $\beta$ required to induce acute activation, a time-course experiment was performed with increasing doses of IL-1 $\beta(0-100 \mathrm{ng} / \mathrm{ml})$. All doses were maintained for $2 \mathrm{~h}$ and removed by multiple washes. Cells were replenished with fresh culture medium and ELISA tests were utilized to measure TIMP-1 at various time points from 2 to $72 \mathrm{~h}$. Figure 1B represents data at 6, 12, 24, and 48 $\mathrm{h}$ postactivation. Analysis of multiple donors demonstrated significant upregulation of TIMP-1 in primary human astrocytes upon immune activation with IL-1 $\beta$. At 20 and $50 \mathrm{ng} /$ $\mathrm{ml}$, there was no significant difference in TIMP-1 levels at $24 \mathrm{~h}$; hence, $20 \mathrm{ng} / \mathrm{ml}$ was utilized for all further experiments. Three independent donors were analyzed and RT-PCR analysis showed increased levels of TIMP-1 RNA (Fig. 1C). Each donor was analyzed in duplicate determinations and untreated controls were maintained in parallel. Reverse zymography performed on three independent donors also showed significant upregulation in TIMP-1 levels ( $P=0.05 ; \mathrm{n}=3)$; however, TIMP-2 was not affected (Fig. 1E). Since reverse zymography measures only free TIMP-1 and not MMP-bound TIMP-1, we also assayed total TIMP-1 protein (Fig. 1D). Two independent donors were analyzed in parallel and each condition was analyzed in triplicate. IL-1 $\beta$ led to significant upregulation in total TIMP-1 ( $P$ $=0.0015)$. The data demonstrate that IL- $1 \beta$ activation is a stimulus for TIMP- 1 upregulation in human astrocytes.

\section{Astrocytes, TIMP-1, and HIV-1}

We examined the effect of HIV-1 on TIMP-1 production in astrocytes. A panel of R5 macrophage tropic isolates was utilized as all HIV-1 strains isolated from the brain thus far are macrophage tropic. HIV-1 JRFL $_{\text {and HIV-1 }}$ DJV, both brain-derived HIV-1 strains, led to significant increases in TIMP-1 secretion from treated astrocytes $(P<0.05$; Fig. $2 \mathrm{~A})$. In order to mimic more closely the conditions present in vivo, culture supernatants from HIV-1-infected macrophages with and without IL- $1 \beta$ activation were used. Consistent with our prior results with IL-1 $\beta$ activation (Fig. 1), supernatants from HIV-1-infected macrophages alone led to a significant increase in astrocyte TIMP-1 production $(P<0.05)$. HIV-1-infected and IL-1 $\beta$-activated MDM culture supernatants led to a 1.29-fold increase in astrocyte TIMP-1 production by astrocytes $(P<0.001)$. Figure 2B demonstrates the data obtained from two independent donors. To study the profiles of TIMP-1, CSF from 27 donors was analyzed using a commercially available ELISA that measures total TIMP-1, including free and MMP-bound. TIMP-1 levels in CSF from HIV-1-seropositive patients without neurological impairment $(\mathrm{n}=10)$ was $1.078 \pm 0.09 \mu \mathrm{g} / \mathrm{ml}$ and HAD patients $(\mathrm{n}=$ 
10) was $1.015 \pm 0.08 \mu \mathrm{g} / \mathrm{ml}$ and showed significantly lower reduction $(P<0.01)$ than TIMP-1 levels in seronegative controls ( $\mathrm{n}=7 ; 1.7 \pm 0.25 \mu \mathrm{g} / \mathrm{ml}$; Fig. $2 \mathrm{C})$. Each sample was analyzed in duplicate. Error bars represent SEM. TIMP-2 levels in the CSF samples were below the level of detection by ELISA (data not shown). Brain tissue from a patient with HIVE was obtained by rapid autopsy and protein extracts were prepared from basal ganglia, white matter, and cerebellum. Cerebellum served as a probable region unaffected by infiltration of macrophages and microglial infection and activation. TIMP-1 levels were measured by ELISA (Fig. 2D). The results were consistent with our observations in CSF. In deep white matter, levels of TIMP-1 were significantly lower $(P<0.05)$ than those in the cerebellum. Also, a trend toward reduced levels of TIMP-1 was observed in basal ganglia, although this was not significant. This clearly shows that levels of TIMP-1 were significantly reduced in HAD as compared to controls.

\section{TIMP-1 Expression in Brain}

Our results indicated that TIMP-1 levels in immune-activated astrocytes were different than those observed in CSF. This prompted investigation of the relationship between TIMP-1 in human brain tissue with levels of GFAP and IL-1 $\beta$. Protein lysates were prepared from basal ganglia and frontal cortex white matter from control donors ( $\mathrm{n}=5)$, HIV-1-infected individuals without cognitive impairment $(n=12)$, and HAD patients $(n=16)$. Levels of total protein were assayed as described by the standard BCA method. Total RNA was extracted from these and additional cases for the determination of GAPDH, GFAP, and IL-1 $\beta$ transcripts. RT-PCR was performed to assay the levels of GFAP (data not shown), and quantikine mRNA ELISAs were utilized to measure IL- $1 \beta$ and GAPDH levels for correlative analyses. An ELISA for TIMP-1 was used to measure total TIMP-1 in brain tissue. Notably, TIMP-1 levels in brain tissue were significantly lower in $\mathrm{HIV}^{+}$-seropositive and HAD patients when compared to controls $(P<0.001$; Fig. 3A). In addition, MMP-2 levels showed the opposite trend (Fig. 3B) and were significantly higher in $\mathrm{HIV}^{+}$individuals $(\mathrm{n}=8 ; P<0.01)$ and HIVE brains $(\mathrm{n}=16 ; P<0.0001)$. Since our data showed a significant increase in TIMP-1 levels in astrocytes stimulated with IL-1 $\beta$ (Fig. 1), we measured the levels of IL- $1 \beta$ transcripts in the RNA samples prepared from these specimens and correlated the levels of IL-1 $\beta$ with those of GFAP. Figure 3C shows significant upregulation in IL-1 $\beta$ RNA in HIV-1-seropositive individuals and HAD patients as compared to seronegative controls $(P<0.001)$. In addition, there was a positive correlation in levels of IL-1 $\beta$ with GFAP $(r=0.6$; Fig. 3D). Although not significant, it demonstrated a positive correlation $(P=0.051)$. When TIMP-1 was correlated to GFAP in equivalent brain regions, a negative correlation with a Spearman $\mathrm{r}=-0.6273(P=0.0388)$ was observed (Fig. 3E). As a corollary to these observations, there was a negative correlation with TIMP- 1 and IL- $1 \beta$ (r $=-0.5364 ;$ Fig. 3F). For all experiments, each sample was analyzed in duplicate and the values were normalized to either total protein or GAPDH. For correlative analyses, normalized average values were obtained from duplicates of each sample.

\section{Astrocyte Activation and TIMP-1 Expression}

Our investigation of acute activation of astroctyes and its correlation to biological specimens yielded two important yet incongruent observations. First, TIMP-1 levels in human brain RNA were significantly lower in both HIV-1-infected patients with or without HAD as compared to seronegative controls. Second, astrocytes activated with IL- $1 \beta$ demonstrated a significant increase in TIMP-1 production. We argued the reason for this disparity was the fact that in vivo conditions represent chronic activation obtained as a result of a continuous disease process rather than acute activation as portrayed in our in vitro system. Furthermore, these observations would be biologically consistent if there was a differential response of astrocytes to acute and chronic activation. This led us to investigate TIMP-1 regulation in astrocytes with chronic activation. We hypothesized that we would see a differential pattern 
in TIMP-1 profiles with chronic IL-1 $\beta$ activation (Fig. 4). TIMP-1 levels in astrocytes increased significantly and reached a plateau. However, TIMP-1 levels in cells exposed to IL- $1 \beta$ on a chronic basis started to decline beyond day 20 (Fig. 4A). Significant reductions were observed in TIMP-1 levels up to day 26 following a peak plateau at day $20(P<0.001)$. To correlate this down-regulation in TIMP-1 with MMP production from cells, MMP-2 (Fig. 4B) and MMP-1 (Fig. 4C) were assayed from the same samples. It is noteworthy that MMP-2 levels mirrored the trend observed for TIMP-1 and declined significantly after day $20(P<0.001)$. However, MMP-1 levels continued to increase with chronic IL-1 $\beta$ exposure and were significantly higher from day $21(P<0.01)$ and days $22-26(P<0.001)$. These data suggest that there is differential regulation of TIMP-1 in astrocytes in response to acute versus chronic immune activation. MMP-1 levels continued to increase even though MMP-2 showed decreased levels. These data suggest an imbalance in the MMP-TIMP regulation under chronic activation.

\section{DISCUSSION}

This study examined the expression of TIMP-1 in HAD. Since TIMP-1 is responsible for the regulation of MMP activity and can be affected by immune activation, it provides a compensatory mechanism against excessive ECM degradation. In the CNS, astrocytes are most likely to express TIMP-1 given their supportive role. Reactive astrogliosis is, by default, the most stereotypical response to all types of CNS damage, ranging from stab injury to inflammation (Mucke and Eddleston, 1993; Ridet et al., 1997).

Matrix metalloproteinases are thought to play an important role in the pathogenesis of HAD and other neurodegenerative disorders, specifically in blood-brain barrier compromise and degradation of ECM (Dhawan et al., 1995; Berman et al., 1999; Conant et al., 1999;

Dezzutti et al., 1999; Liuzzi et al., 2000; Sporer et al., 2000; Ghorpade et al., 2001; Toschi et al., 2001). Several groups, including ours, have investigated the levels of MMP-2 and MMP-9 in CSF, plasma, or brain tissue of HIV-1 patients (Conant et al., 1999; Ghorpade et al., 2001). However, there is a striking paucity of information on the regulation of the matrix-degrading enzymes in the tissue microenvironment by their inhibitors, TIMPs. Previously, we reported that differentiation of monocytes into macrophage-like cells led to concomitant upregulation of MMPs and TIMP-1. This suggests a mechanism for homeostasis intrinsic to the regulation of these enzymes (Ghorpade et al., 2001). This report studied TIMP-1 regulation in primary human brain astrocytes following activation with IL-1 $\beta$. IL-1 $\beta$, as a proinflammatory cytokine, is relevant to HIV-1 (Tyor et al., 1993; Vitkovic et al., 1995) and in astrocytes its production is regulated by an autocrine loop (Vitkovic et al., 1995). As a result, small amounts of IL-1 $\beta$ can lead to further activation of resident astrocytes at the site of injury. Consistent with our hypothesis, we observed significant upregulation in TIMP-1 mRNA, protein, and enzyme activity in IL- $1 \beta$-activated astrocytes. In HAD, a finite percentage of astrocytes demonstrate restrictive infection and are believed to be a reservoir of HIV-1 in the CNS (Saito et al., 1994). Astrocytes also express a variety of chemokine receptors that may bind the virus for example CXCR4 (Zheng et al., 1999) and such ligation of cell surface receptors may alter cellular function. Our experiments show that astrocytes exposed to HIV-1 preparations also led to significant increases in TIMP-1 production similar to acute activation. This suggests that astrocytes are likely to respond to HIV-1 in vivo and upregulate TIMP-1 as a countermeasure. Whether a combination of virus and immune activation would demonstrate a synergistic response in TIMP-1 production in astrocytes would be important to the disease process. Although the virus is necessary for the neurological manifestations of the disease, the cellular processes are known to contribute to the disease mechanism significantly (Gendelman et al., 1988a; Petito et al., 1999). The virion preparations utilized for testing the regulation of TIMP-1 in astrocytes in context of HIV-1 were propagated in mononuclear phagocytes and then 
purified with centrifugation and multiple washes. Thus, one could argue that these virus preparations still contained remnants of secreted macrophage products. In this event, perhaps the response obtained from astrocytes is truly a reaction to immune products of infected macrophages and has nothing to do with HIV-1. To address this issue, it will be important to assay the effects of HIV-1 viral proteins such as gp120 on TIMP-1 production by astrocytes. In addition, our experiments with culture supernatants cross-transfer from infected and activated macrophages suggest a synergistic effect on TIMP-1 production in human astrocytes.

When we studied biological samples from patients with HIV-1 infection, we observed that TIMP-1 levels in CSF were higher in controls, whereas the levels of TIMP-1 in plasma were significantly higher in HAD and HIV-1 seropositive patients (data not shown). However, we did not observe a parallel increase in CSF TIMP-1 levels. This was in contrast to our in vitro data since we observed that exposure of astrocytes to immune stimuli or HIV-1 led to increased TIMP-1 levels. In addition, HIV patients show elevated MMP levels in CSF (Conant et al., 1999). According to our hypothesis, a biological countermeasure and an increase in TIMP-1 levels in the CSF should have been detected. We first wanted to confirm that the levels of TIMP-1 observed in the CSF were truly reflective of the phenomena in the brain. We thus studied the brain tissue and examined transcripts and protein levels of TIMP-1 by using total RNA and brain tissue lysates from seronegative controls, HIV-1infected and HAD patients. These studies confirmed reduced TIMP-1 levels in HIV patients. To verify whether regional differences exist in TIMP-1 profiles in the brain, different areas of the brain from a patient who died of HIVE were examined. These demonstrated lower levels of TIMP-1 in areas with higher GFAP such as the white matter. Moreover, IL-1 $\beta$ levels in brain tissue samples correlated significantly and positively with GFAP levels, which in turn had a negative correlation with TIMP-1. We believe the following contribute to this observation. First, the CNS has a potential built-in mechanism of balancing higher MMP production in the context of immune activation and thus can protect the tissue from ECM breakdown. Second, and more interestingly, our data suggest that although the prospects of this mechanism appear excellent in the context of acute activation, chronic activation as reflected in postmortem CSF and brain tissue leads to an impairment of this protective response. It is possible that the increases in TIMP-1 production in IL-1 $\beta$-activated astrocytes may be due only to the fact that these cells are derived from fetal brain tissue and that adult astrocytes would respond differently. However, it is unlikely since other studies that have investigated the role of TIMP-1 in animal CNS injury models have shown reactive astrocytes to express TIMP-1 (Rivera et al., 1997; Pagenstecher et al., 1998; Jaworski, 2000; Rathke-Hartlieb et al., 2000). Human astroglioma cells also produce TIMP-1 (Groft et al., 2001). Although the role of TIMP-1 in the pathobiology of glioma cells is incompletely understood, it is believed that overex-pressed TIMPs reduce tumor invasion and metastasis in vivo. This confirms that human adult astrocytes do possess the ability to express TIMP-1 in a conducive environment. Indeed, in the CNS, interactions with HTLV-1-infected Tlymphocytes lead to upregulation of TIMP-1 mRNA in reactive astrocytes (Szymocha et al., 2000).

Since postmortem CSF and brain tissue represent endpoints of a chronic activation process and in vitro IL- $1 \beta$ activation represents an acute activation model, we examined whether TIMP-1 in astrocytes is differentially regulated in response to acute versus chronic activation. Indeed, chronic activation led to reduced TIMP-1 levels in the extracellular milieu, including early time points that otherwise lead to significant increases in TIMP-1 levels in response to a shorter exposure of IL-1 $\beta$ (Figs. 1 and 4). Our results suggest that in $\mathrm{HAD}$, activated astrocytes that accumulate at the sites of immune activation mount a counteractive response in the form of TIMP-1 production. However, with time and chronic activation, this homeostasis is perturbed, leading to a duality in TIMP-1 regulation. Indeed, 
some of the MMPs that are produced by activated cells, such as MMP-1, still continued to increase. Together, an increase in MMP and a concomitant decrease in TIMP would ultimately result in exacerbated ECM degradation in the brain parenchyma. Indeed, our results verify this idea as the MMP-2 levels in brain lysates of HIVE patients were significantly higher and the TIMP-1 levels in the same samples were significantly lower as compared to control cases. A variety of ECM proteins in brain tissue of HIVE patients have been studied and have shown a significant reduction in ECM proteins in HAD patients as compared to $\mathrm{HIV}^{+}$-seropositive and control donors (Belichenko et al., 1997). Whether chronic HIV-1 exposure leads to a downregulation in TIMP-1 levels in astrocytes still awaits further investigation.

TIMP-1 plays a very important role in different tissue remodeling events and in inflammation due to its involvement in the cleavage and release of cytokines and growth factors from cellular membranes. In addition, TIMP-1 is known to aid in cell survival. Thus, astrocyte-regulated TIMP-1 expression early in the HAD brain may have multifaceted functions, and it may potentially act as a survival factor for neurons.

\section{Acknowledgments}

The authors thank the NIH National NeuroAIDS Consortium and the Center for Neurovirology and Neurodegenerative Disorders Brain Bank for the biological specimens used in this study. They also thank Ms. Julie Ditter and Ms. Robin Taylor for excellent administrative support and acknowledge the contribution of all individuals involved in the Rapid Autopsy Program. Supported by 77408-25-PFR from the Pediatrics AIDS Foundation, and R37NS36126 (to H.E.G.). NS31492-06 from National Institute of Neurological Disease \& Stroke (NINDS) (to A.G.).

\section{REFERENCES}

Belichenko PV, Miklossy J, Celio MR. HIV-I induced destruction of neocortical extracellular matrix components in AIDS victims. Neurobiol Dis. 1997; 4:301-310. [PubMed: 9361307]

Berman NE, Marcario JK, Yong C, Raghavan R, Raymond LA, Joag SV, Narayan O, Cheney PD. Microglial activation and neurological symptoms in the SIV model of NeuroAIDS: association of MHC-II and MMP-9 expression with behavioral deficits and evoked potential changes. Neurobiol Dis. 1999; 6:486-498. [PubMed: 10600404]

Bloomston M, Shafii A, Zervos EE, Rosemurgy AS. TIMP-1 overexpression in pancreatic cancer attenuates tumor growth, decreases implantation and metastasis, and inhibits angiogenesis. J Surg Res. 2002; 102:39-44. [PubMed: 11792150]

Bode W, Fernandez-Catalan C, Nagase H, Maskos K. Endoproteinase-protein inhibitor interactions. APMIS. 1999a; 107:3-10. [PubMed: 10190274]

Bode W, Fernandez-Catalan C, Grams F, Gomis-Ruth FX, Nagase H, Tschesche H, Maskos K. Insights into MMP-TIMP interactions. Ann NY Acad Sci. 1999b; 878:73-91. [PubMed: 10415721]

Brew K, Dinakarpandian D, Nagase H. Tissue inhibitors of metalloproteinases: evolution, structure and function. Biochim Biophys Acta. 2000; 1477:267-283. [PubMed: 10708863]

Bugno M, Witek B, Bereta J, Bereta M, Edwards DR, Kordula T. Reprogramming of TIMP-1 and TIMP-3 expression profiles in brain microvascular endothelial cells and astrocytes in response to proinflammatory cytokines. FEBS Lett. 1999; 448:9-14. [PubMed: 10217399]

Canki M, Thai JN, Chao W, Ghorpade A, Potash MJ, Volsky DJ. Highly productive infection with pseudotyped human immunodeficiency virus type 1 (hiv-1) indicates no intracellular restrictions to hiv-1 replication in primary human astrocytes. J Virol. 2001; 75:7925-7933. [PubMed: 11483737]

Chadderton T, Wilson C, Bewick M, Gluck S. Evaluation of three rapid RNA extraction reagents: relevance for use in RT-PCR's and measurement of low level gene expression in clinical samples. Cell Mol Biol. 1997; 43:1227-1234. [PubMed: 9489949]

Cheng-Mayer C, Levy JA. Distinct biological and serological properties of human immunodeficiency viruses from the brain. Ann Neurol. 1988; 23(Suppl):S58-S61. [PubMed: 3258140] 
Conant K, McArthur JC, Griffin DE, Sjulson L, Wahl LM, Irani DN. Cerebrospinal fluid levels of MMP-2, 7, and 9 are elevated in association with human immunodeficiency virus dementia. Ann Neurol. 1999; 46:391-398. [PubMed: 10482270]

Dezzutti CS, Swords WE, Guenthner PC, Sasso DR, Wahl LM, Drummond AH, Newman GW, King $\mathrm{CH}$, Quinn FD, Lal RB. Involvement of matrix metalloproteinases in human immunodeficiency virus type 1-induced replication by clinical Mycobacterium avium isolates. J Infect Dis. 1999; 180:1142-1152. [PubMed: 10479141]

Dhawan S, Wahl LM, Heredia A, Zhang Y, Epstein JS, Meltzer MS, Hewlett IK. Interferon-gamma inhibits HIV-induced invasiveness of monocytes. J Leukoc Biol. 1995; 58:713-716. [PubMed: 7499970]

Dickson DW, Lee SC, Mattiace LA, Yen SH, Brosnan C. Micro-glia and cytokines in neurological disease, with special reference to AIDS and Alzheimer's disease. Glia. 1993; 7:75-83. [PubMed: 8423065]

Fassina G, Ferrari N, Brigati C, Benelli R, Santi L, Noonan DM, Albini A. Tissue inhibitors of metalloproteases: regulation and biological activities. Clin Exp Metastasis. 2000; 18:111-120. [PubMed: 11235986]

Gelbard HA, Nottet HS, Swindells S, Jett M, Dzenko KA, Genis P, White R, Wang L, Choi YB, Zhang D, et al. Platelet-activating factor: a candidate human immunodeficiency virus type 1induced neurotoxin. J Virol. 1994; 68:4628-4635. [PubMed: 8207837]

Gendelman HE, Leonard JM, Dutko F, Koenig S, Khillan J, Meltzer MS. Immunopathogenesis of human immunodeficiency virus infection in the central nervous system. Ann Neurol. 1988a; 23:S78-S81. [PubMed: 3348602]

Gendelman HE, Orenstein JM, Martin MA, Ferrua C, Mitra R, Phipps T, Wahl LA, Lane HC, Fauci AS, Burke DS, et al. Efficient isolation and propagation of human immunodeficiency virus on recombinant colony-stimulating factor 1-treated monocytes. J Exp Med. 1988b; 167:1428-1441. [PubMed: 3258626]

Gendelman HE, Persidsky Y, Ghorpade A, Limoges J, Stins M, Fiala M, Morrisett R. The neuropathogenesis of AIDS dementia complex. AIDS. 1997; 11:S35-S45. [PubMed: 9451964]

Ghorpade A, Nukuna A, Che M, Haggerty S, Persidsky Y, Carter E, Carhart L, Shafer L, Gendelman HE. Human immunodeficiency virus neurotropism: an analysis of viral replication and cytopathicity for divergent strains in monocytes and microglia. J Virol. 1998; 72:3340-3350. [PubMed: 9525661]

Ghorpade A, Persidskaia R, Suryadevara R, Che M, Liu XJ, Persidsky Y, Gendelman HE. Mononuclear phagocyte differentiation, activation, and viral infection regulate matrix metalloproteinase expression: implications for human immunodeficiency virus type 1-associated dementia. J Virol. 2001; 75:6572-6583. [PubMed: 11413325]

Gomez DE, Alonso DF, Yoshiji H, Thorgeirsson UP. Tissue inhibitors of metalloproteinases: structure, regulation and biological functions. Eur J Cell Biol. 1997; 74:111-122. [PubMed: 9352216]

Groft LL, Muzik H, Rewcastle NB, Johnston RN, Knauper V, Lafleur MA, Forsyth PA, Edwards DR. Differential expression and localization of TIMP-1 and TIMP-4 in human gliomas. Br J Cancer. 2001; 85:55-63. [PubMed: 11437402]

Heinzinger N, Baca-Regen L, Stevenson M, Gendelman HE. Efficient synthesis of viral nucleic acids following monocyte infection by HIV-1. Virology. 1995; 206:731-735. [PubMed: 7831833]

Jaworski DM. Differential regulation of tissue inhibitor of metalloproteinase mRNA expression in response to intracranial injury. Glia. 2000; 30:199-208. [PubMed: 10719361]

Johnatty RN, Taub DD, Reeder SP, Turcovski-Corrales SM, Cottam DW, Stephenson TJ, Rees RC. Cytokine and chemokine regulation of proMMP-9 and TIMP-1 production by human peripheral blood lymphocytes. J Immunol. 1997; 158:2327-2333. [PubMed: 9036981]

Kalter DC, Nakamura M, Turpin JA, Baca LM, Hoover DL, Dieffen-bach C, Ralph P, Gendelman HE, Meltzer MS. Enhanced HIV replication in macrophage colony-stimulating factor-treated monocytes. J Immunol. 1991; 146:298-306. [PubMed: 1701795] 
Kintscher U, Kon D, Wakino S, Goetze S, Graf K, Fleck E, Hsueh WA, Law RE. Doxazosin inhibits monocyte chemotactic protein 1-directed migration of human monocytes. J Cardiovasc Pharmacol. 2001; 37:532-539. [PubMed: 11336104]

Kossakowska AE, Edwards DR, Lee SS, Urbanski LS, Stabbler AL, Zhang CL, Phillips BW, Zhang Y, Urbanski SJ. Altered balance between matrix metalloproteinases and their inhibitors in experimental biliary fibrosis. Am J Pathol. 1998; 153:1895-1902. [PubMed: 9846979]

Koyanagi Y, Miles S, Mitsuyasu RT, Merrill JE, Vinters HV, Chen IS. Dual infection of the central nervous system by AIDS viruses with distinct cellular tropisms. Science. 1987; 236:819-822. [PubMed: 3646751]

Kugler A. Matrix metalloproteinases and their inhibitors. Anticancer Res. 1999; 19:1589-1592. [PubMed: 10365151]

Liuzzi GM, Mastroianni CM, Santacroce MP, Fanelli M, D'Agostino C, Vullo V, Riccio P. Increased activity of matrix metalloproteinases in the cerebrospinal fluid of patients with HIV-associated neurological diseases. J Neurovirol. 2000; 6:156-163. [PubMed: 10822329]

Manthrope M, Fagnani R, Skaper SD, Varon S. An automated colorimetric microassay for neurotrophic factors. Dev Brain Res. 1986; 25:191-198.

Mucke L, Eddleston M. Astrocytes in infectious and immune-mediated diseases of the central nervous system. Faseb J. 1993; 7:1226-1232. [PubMed: 8405808]

Norenberg MD. Astrocyte responses to CNS injury. J Neuropathol Exp Neurol. 1994; 53:213-220. [PubMed: 8176405]

Pagenstecher A, Stalder AK, Kincaid CL, Shapiro SD, Campbell IL. Differential expression of matrix metalloproteinase and tissue inhibitor of matrix metalloproteinase genes in the mouse central nervous system in normal and inflammatory states. Am J Pathol. 1998; 152:729-741. [PubMed: 9502415]

Persidsky Y, Ghorpade A, Rasmussen J, Limoges J, Liu XJ, Stins M, Fiala M, Way D, Kim KS, Witte MH, Weinand M, Carhart L, Gendelman HE. Microglial and astrocyte chemokines regulate monocyte migration through the blood-brain barrier in human immunodeficiency virus-1 encephalitis. Am J Pathol. 1999; 155:1599-1611. [PubMed: 10550317]

Persidsky Y, Ghorpade A. HIV-1 traffic: cell-free, cell associated and other CNS activating stories. AIDScience online. 2001

Petito CK, Kerza-Kwiatecki AP, Gendelman HE, McCarthy M, Nath A, Podack ER, Shapshak P, Wiley CA. Review: neuronal injury in HIV infection. J Neurovirol. 1999; 5:327-341. [PubMed: 10463855]

Rathke-Hartlieb S, Budde P, Ewert S, Schlomann U, Staege MS, Jockusch H, Bartsch JW, Frey J. Elevated expression of membrane type 1 metalloproteinase (MT1-MMP) in reactive astrocytes following neurodegeneration in mouse central nervous system. FEBS Lett. 2000; 481:227-234. [PubMed: 11007969]

Ridet JL, Malhotra SK, Privat A, Gage FH. Reactive astrocytes: cellular and molecular cues to biological function. Trends Neurosci. 1997; 20:570-577. [PubMed: 9416670]

Rivera S, Tremblay E, Timsit S, Canals O, Ben-Ari Y, Khrestchatisky M. Tissue inhibitor of metalloproteinases-1 (TIMP-1) is differentially induced in neurons and astrocytes after seizures: evidence for developmental, immediate early gene, and lesion response. J Neurosci. 1997; 17:4223-4235. [PubMed: 9151739]

Saito Y, Sharer LR, Epstein LG, Michaels J, Mintz M, Louder M, Golding K, Cvetkovich TA, Blumberg BM. Overexpression of nef as a marker for restriced HIV-1 infection of astrocytes in postmortem pediatric central nervous tissue. Neuorology. 1994; 44:474-481.

Sharpless N, Gilbert D, Vandercam B, Zhou JM, Verdin E, Ronnett G, Friedman E, Dubois-Dalcq M. The restricted nature of HIV-1 tropism for cultured neural cells. Virology. 1992; 191:813-825. [PubMed: 1448925]

Shrikant P, Benos DJ, Tang LP, Benveniste EN. HIV glycoprotein 120 enhances intercellular adhesion molecule-1 gene expression in glial cells: involvement of Janus kinase/signal transducer and activator of transcription and protein kinase C signaling pathways. J Immunol. 1996; 156:13071314. [PubMed: 8558011] 
Sporer B, Koedel U, Paul R, Kohleisen B, Erfle V, Fontana A, Pfister HW. Human immunodeficiency virus type-1 Nef protein induces blood-brain barrier disruption in the rat: role of matrix metalloproteinase-9. J Neuroimmunol. 2000; 102:125-130. [PubMed: 10636480]

Szymocha R, Akaoka H, Brisson C, Beurton-Marduel P, Chalon A, Bernard A, Didier-Bazes M, Belin MF, Giraudon P. Astrocytic alterations induced by HTLV type 1-infected T lymphocytes: a role for Tax-1 and tumor necrosis factor alpha. AIDS Res Hum Retroviruses. 2000; 16:1723-1729. [PubMed: 11080817]

Toschi E, Barillari G, Sgadari C, Bacigalupo I, Cereseto A, Carlei D, Palladino C, Zietz C, Leone P, Sturzl M, Butto S, Cafaro A, Monini P, Ensoli B. Activation of matrix-metalloproteinase-2 and membrane-type-1-matrix- metalloproteinase in endothelial cells and induction of vascular permeability in vivo by human immunodeficiency virus-1 Tat protein and basic fibroblast growth factor. Mol Biol Cell. 2001; 12:2934-2946. [PubMed: 11598182]

Tyor WR, Glass JD, Baumrind N, McArthur JC, Griffin JW, Becker PS, Griffin DE. Cytokine expression of macrophages in HIV-1-associated vacuolar myelopathy. Neurology. 1993; 43:10021009. [PubMed: 8492917]

Vitkovic L, Chatham JJ, da Cunha A. Distinct expressions of three cytokines by IL-1-stimulated astrocytes in vitro and in AIDS brain. Brain Behav Immunol. 1995; 9:378-388.

Vitkovic L, Konsman JP, Bockaert J, Dantzer R, Homburger V, Jacque C. Cytokine signals propagate through the brain. Mol Psychiatry. 2000; 5:604-615. [PubMed: 11126391]

Vos CMP, Gartner S, Ransohoff RM, McArthur JC, Wahl L, Conant K. Matrix metalloproteinase-9 release from monocytes as a function of differentiation. J Immunol. 2000; 109:221-227.

Wojtowicz-Praga SM, Dickson RB, Hawkins MJ. Matrix metal-loproteinase inhibitors. Invest New Drugs. 1997; 15:61-75. [PubMed: 9195290]

Zheng J, Thylin MR, Ghorpade A, Xiong H, Persidsky Y, Cotter R, Niemann D, Che M, Zeng YC, Gelbard HA, Shepard RB, Swartz JM, Gendelman HE. Intracellular CXCR4 signaling, neuronal apoptosis and neuropathogenic mechanisms of HIV-1-associated dementia. J Neuroimmunol. 1999; 98:185-200. [PubMed: 10430052] 

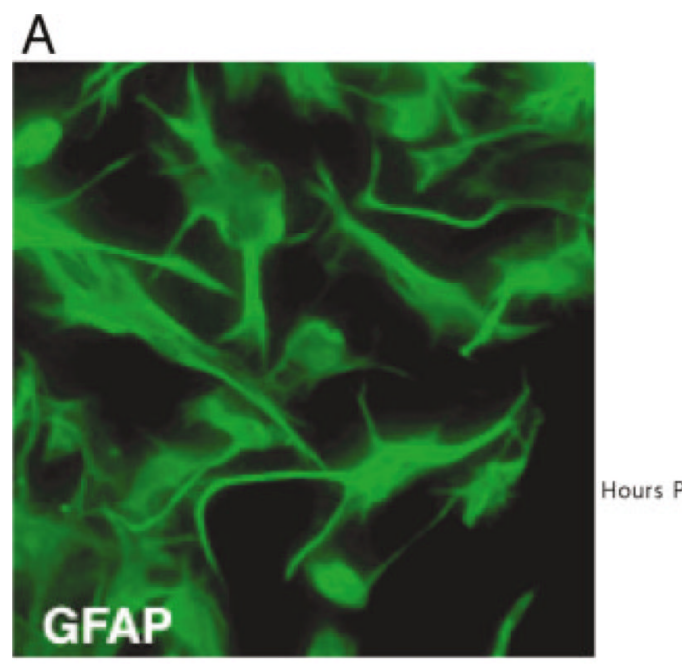

D

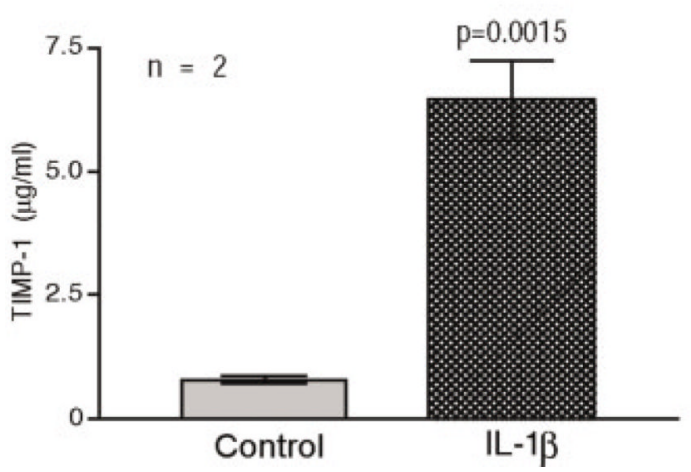

B

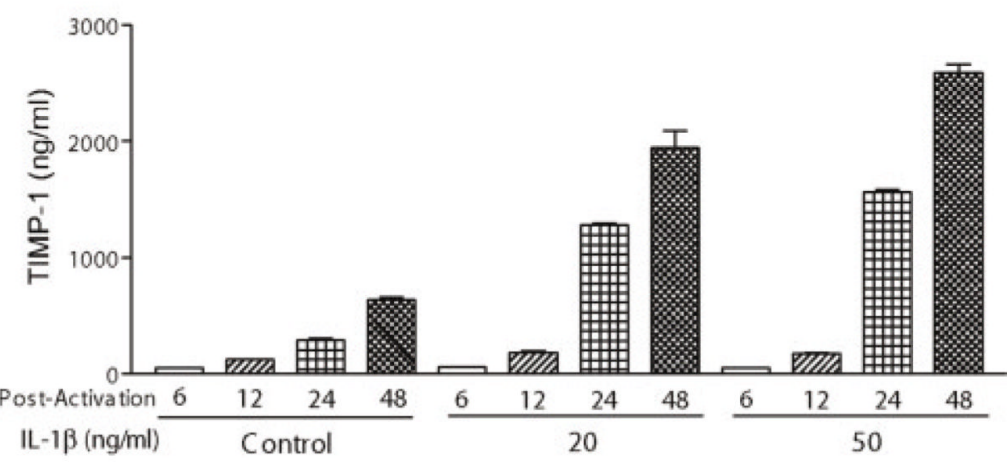

C

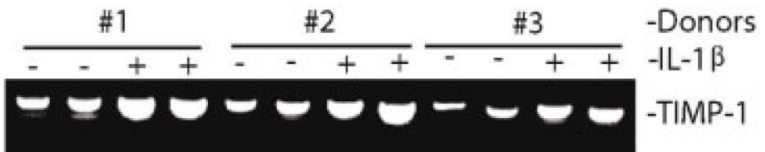

E

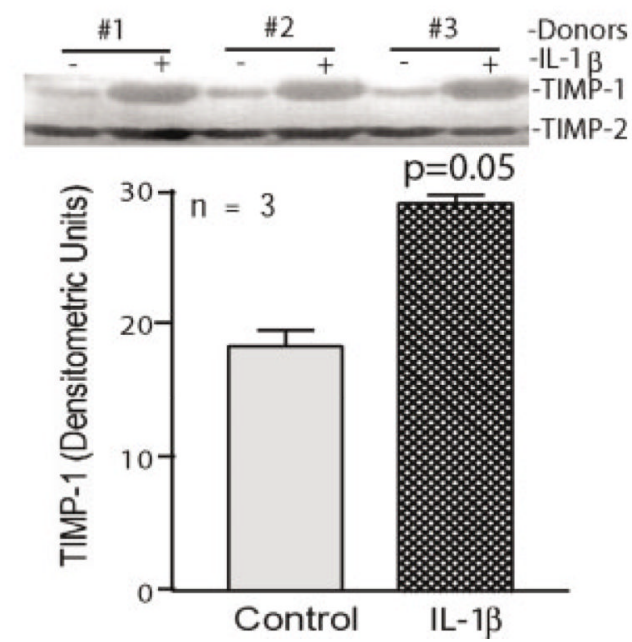

Fig. 1.

Immune activated astrocytes express elevated levels of TIMP-1. Primary human fetal astrocytes were characterized by GFAP staining (A) and activated with IL- $1 \beta$ for $2 \mathrm{~h}$ followed by three washes and the addition of fresh culture medium. MTT activity was used to normalize all measurements. B shows time and dose-responses to IL- $1 \beta$ stimulation. Steady increases in TIMP-1 levels were obtained with multiple IL-1 $\beta$ doses $(10-50 \mathrm{ng} / \mathrm{ml})$ over a period of 6-72 $\mathrm{h}$ postactivation. Data from the 20 and $50 \mathrm{ng} / \mathrm{ml}$ concentrations of IL-1 $\beta$ up to $48 \mathrm{~h}$ are shown. $\mathbf{C}$ demonstrates upregulation of TIMP-1 transcripts as determined by RT-PCR from three independent donors. Each sample was analyzed in duplicate determinations. D demonstrates TIMP-1 levels as measured by ELISA. Replicate supernatants were analyzed by reverse zymography $(\mathbf{E})$. Data from three independent human astrocyte donors are shown. A graph representing the average of the data for all three donors is also provided as part of $\mathrm{C}$ in replicate supernatants as analyzed by reverse zymography. The graph represents an average of two independent donors, each analyzed in triplicate. Significant upregulation of TIMP-1 was demonstrated using both of these techniques ( $P=$ 0.0015 and 0.05 ). Error bars represent standard error of the mean. Statistical analyses were performed with GraphPad Prism 3.0 and ANOVA. 
A

C

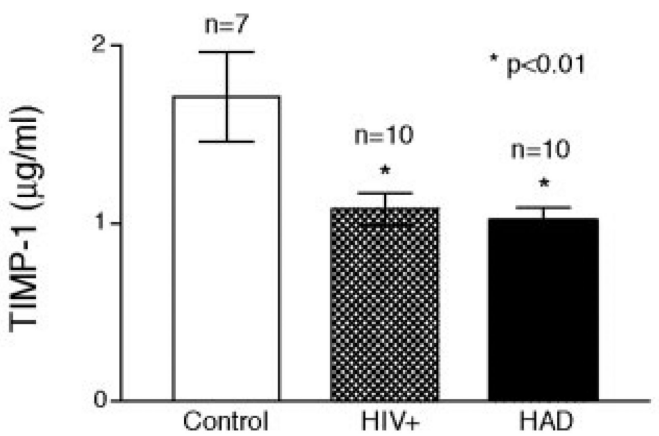

B

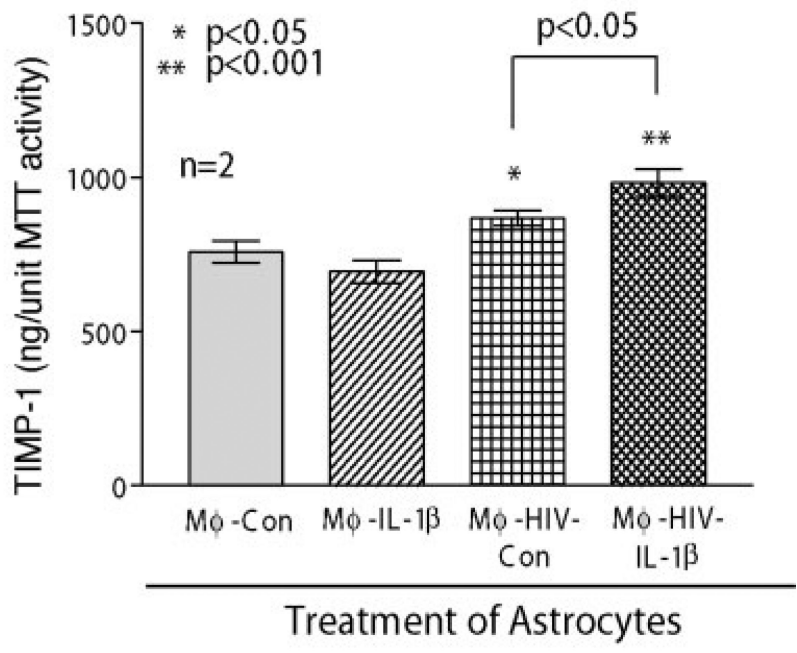

D

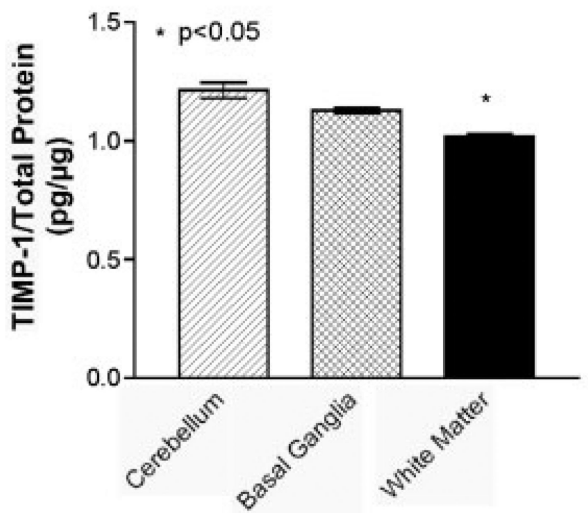

Fig. 2.

TIMP-1, astrocytes, and HIV-1. TIMP-1 levels were measured by ELISA from primary human fetal astrocytes treated with HIV-1 (A) and culture supernatants from virus-infected/ IL-1 $\beta$-activated macrophages (B), CSF from patients with HIV-1 (C) and different areas of the brain from a patient with HIV-1 encephalitis (D). Graphs in A and B each represent data from two independent donors analyzed in triplicate determinations. In C, analysis of CSF samples from 27 donors is shown. HIV-1-seropositive patients without neurological impairment $(\mathrm{n}=10)$ and HAD patients $(\mathrm{n}=10)$ showed significant reduction $(P<0.01)$ in TIMP-1 levels in CSF when compared to seronegative controls $(n=7)$. D demonstrates regional TIMP-1 expression in an HIVE subject. Protein was extracted from cerebellum, basal ganglia, and white matter. TIMP-1 levels were measured in triplicate. Levels of TIMP-1 in white matter were significantly lower as compared to those in cerebellum $(P<$ 0.05). Error bars represent SEM. Statistical analyses were performed using GraphPad Prism 3.0 and one-way ANOVA. 

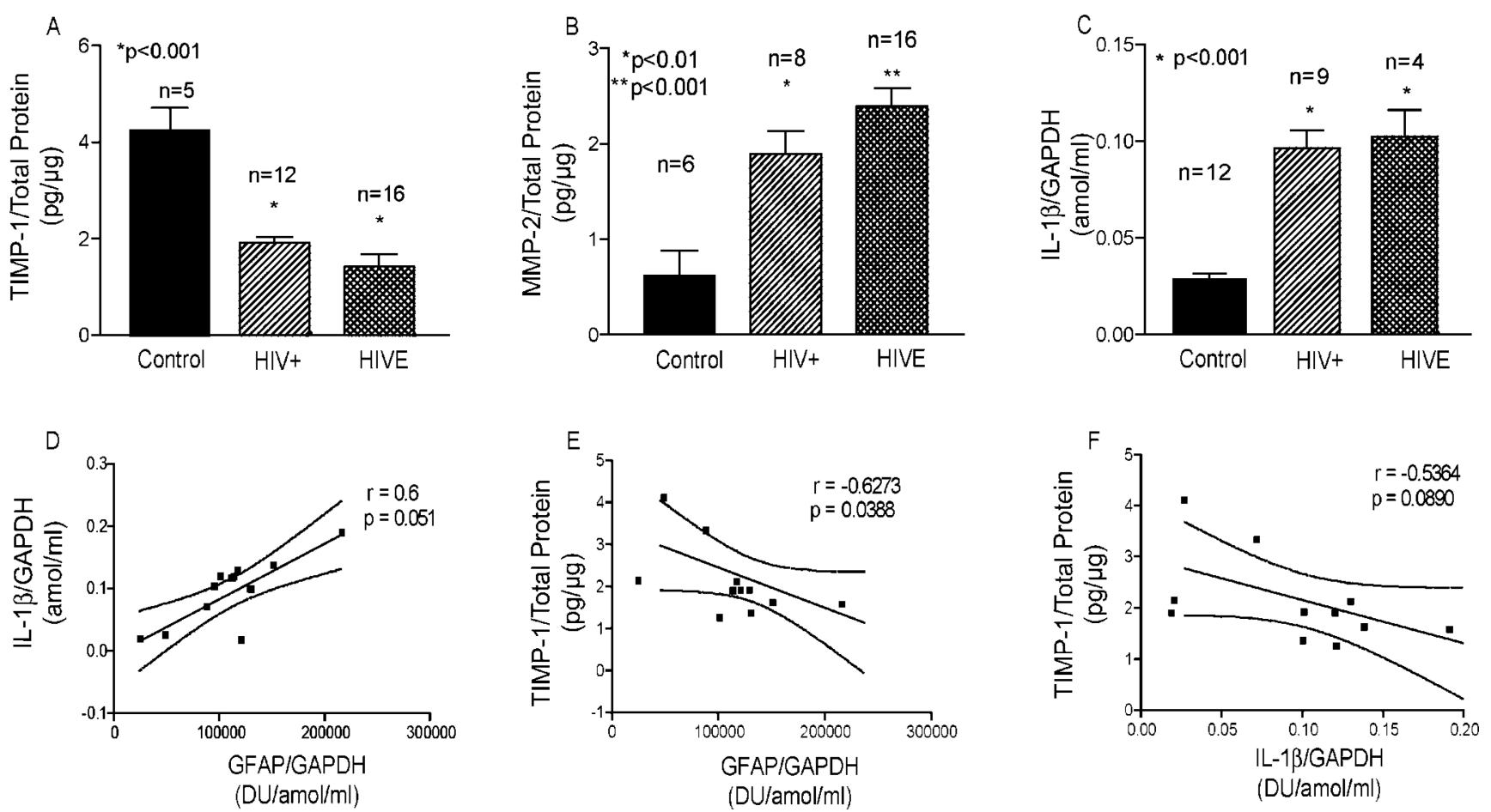

Fig. 3.

Levels of TIMP-1 in human brain tissue. Protein extracts and total RNA isolated from human autopsy brain tissue obtained from control donors, HIV-1-seropositive individuals without cognitive impairment, and HIVE brains were analyzed HIV ${ }^{+}$for TIMP-1 and MMP- 2 by ELISA, and for GAPDH and IL-1 $\beta$ by quantikine mRNA ELISA. GFAP levels were quantitated (data not shown). Each sample was analyzed in duplicate determinations for the ELISA and for RT-PCR. TIMP-1 levels were normalized to total protein content. GAPDH was used to normalize mRNA data sets. Data were analyzed with GraphPad Prism 3.0 using one-way analysis of variance for multiple comparisons. Correlation was evaluated with Spearman's coefficient of correlation for nonparametric comparisons. $\mathbf{A}$ and $\mathbf{B}$ show TIMP-1 and MMP-2 protein levels in brain lysates and $\mathbf{C}$ demonstrates normalized IL-1 $\beta$ transcript levels. D depicts correlation of normalized IL-1 $\beta$ to GFAP. $\mathbf{E}$ shows correlation of normalized TIMP-1 levels to normalized GFAP levels. $\mathbf{F}$ is the correlation of normalized TIMP-1 to IL-1 $\beta$. 

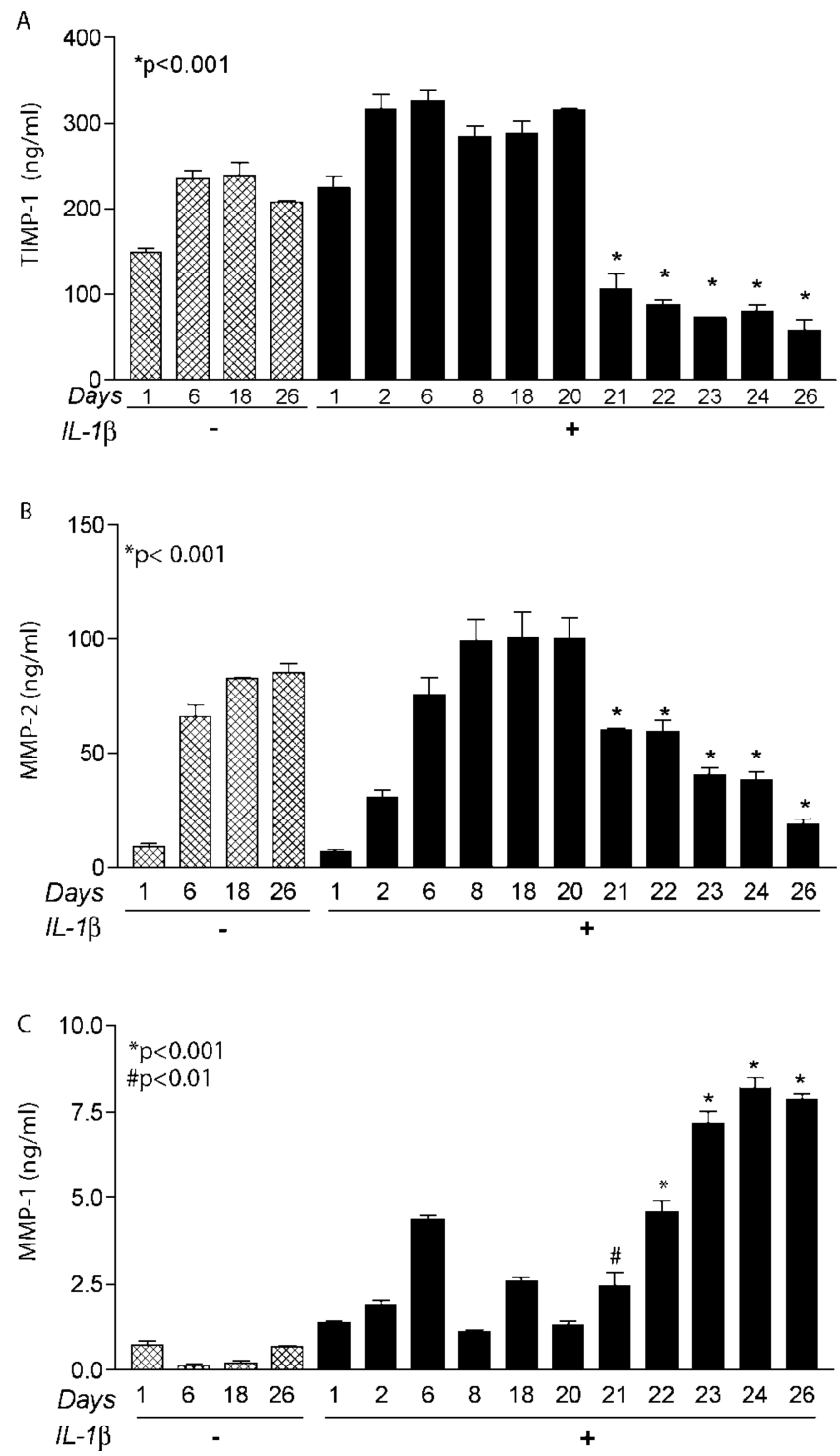

Fig. 4.

Acute and chronic activation stimulate differential expression of TIMP-1, MMP-2, and MMP-1 in human astrocytes. In order to assess the effect of chronic immune activation on TIMP-MMP balance, astrocytes were cultured for different days, as indicated, in media with or without $20 \mathrm{ng} / \mathrm{ml}$ IL- $1 \beta$ and TIMP-1 profiles were compared. Control cells cultured in the absence of IL-1 $\beta$ were maintained in parallel. Culture medium was completely exchanged daily with media supplemented with or without IL-1 $\beta$. All culture super-natant samples were collected and cellular MTT activity was measured. Supernatant samples were analyzed using TIMP-1 (A), MMP-2 (B), and MMP-1 (C) ELISA kits. Each time point was performed in independent triplicate determinations. Data were analyzed with GraphPad Prism 3.0 and one-way ANOVA. Error bars represent standard error of the mean. The effect of chronic activation was evaluated using three independent astrocyte donors. 